\title{
Director's Preface
}

Over millennia, we as humans have gone through a number of fundamental transformations. That from hunter-gatherer to farmer was probably the most dramatic and far-reaching in human history. This is the transformation that the Penn Museum's Middle East Galleries explore: the story of how ancient peoples abandoned ways of life thousands of years old to stay in the same place year-round.

The story of this geographic region and network of ancient civilizations is one that has resonance to all of us. Ten thousand years ago, in the fertile crescent of the Middle East, one of the most transformative points in our human history was set in motion: the domestication of plants and animals prompted the shift from hunting and gathering to farming, establishing the first settled societies. Villages developed, then towns, then the world's first cities. The decision of ancient Mesopotamian peoples to stay in one place dramatically sped up human innovation-writing and mathematics developed for recordkeeping, irrigation for farming, construction techniques for more and more buildings, metallurgy and pottery for tools and domestic items. It also introduced many of the issues of human societies that we continue to address today, like social inequality, warfare, and poverty.

This is one of the most pivotal parts of the human story. We often look at the Industrial Revolution as the turning point in human history, when a much earlier, equally important shift happens in the Neolithic Period-which is when the Middle East Galleries begin their story. The next several thousand years, which the Middle East Galleries illuminate in great detail, are essential to understanding our contemporary society-more specifically, to understanding how we became city dwellers. This understanding is particularly relevant as more and more people come to live in cities each year.

The story of how our modern urbanized world can be traced to developments in ancient Mesopotamian societies is one the Penn Museum can tell uniquely well. In fact, the Museum was founded to house artifacts from the first U.S.-led expedition to Nippur (in modern-day Iraq) in 1889. Penn archaeologists went on to excavate an unparalleled constellation of dozens of sites in the region, unearthing objects that illuminate ways of life thousands of years old that still resonate with us today. More than $95 \%$ of the artifacts on display in the Middle East Galleries were excavated by Penn archaeologists, which means that we have the unique advantage of displaying these objects in the full context of their excavation records. The Galleries share crucial details about who made and used them, bringing ancient civilizations to life.

Many of these objects are among our finest not just from the region but from anywhere in the world. They are masterpieces of craftsmanship and artistry, like the evocative "Ram in the Thicket" statuette (p. 207), for instance, and delicate obsidian bowl (seen below). Alongside these masterpieces are everyday objects remarkable in their ability to bridge the millennia-to conjure the daily lives of ancient people who lived thousands of year ago. Visitors are greeted at the gallery entrance by a brick containing a single footprint left by a worker in the city of Ur 4,000 years ago (p. ii). One of the world's oldest wine jars (p. 1) is among the first objects encountered after that introduction. Children's toys, receipts of sale, farming implements, sewer pipes, household dishes - all of these are found throughout the Galleries, and in this volume.

We invite our visitors to the Middle East Galleries to make connections with these ancient peoples through their objects showcased right here in the Museum. And we extend that invitation, through this book, to you. I hope that you will enjoy engaging with these fascinating artifacts and their stories as much as I do.

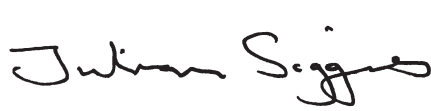

JULIAN SIGGERS, PH.D. WILLIAMS DIRECTOR

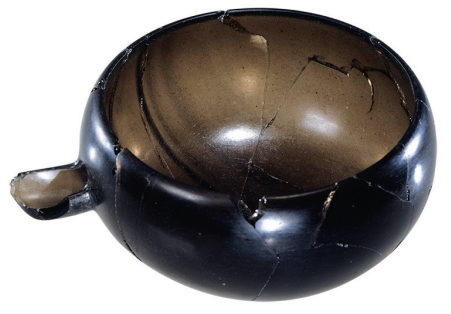




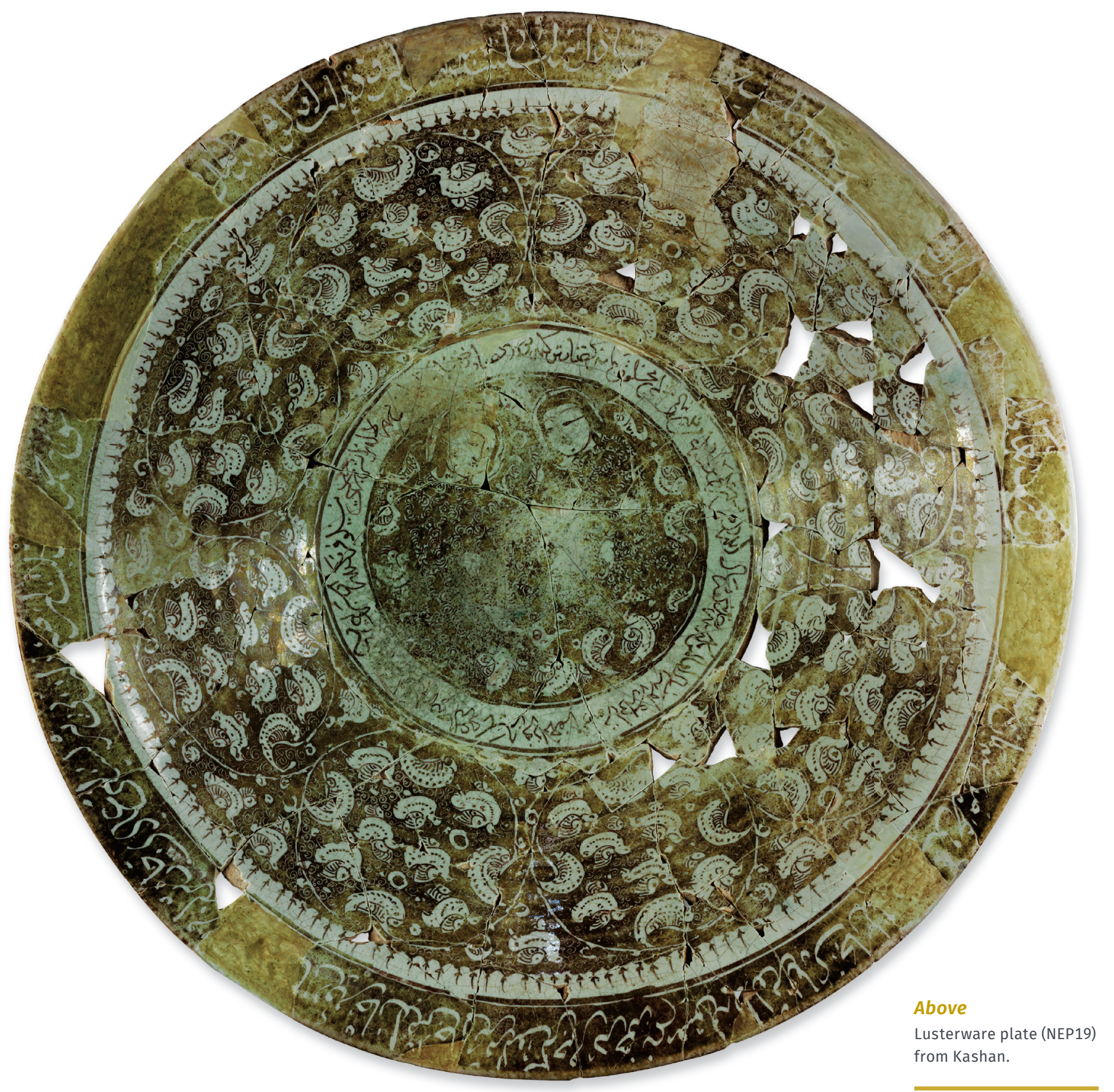

